This is an electronic reprint of the original article. This reprint may differ from the original in pagination and typographic detail.

Author(s): Lehtinen, Antti; Viiri, Jouni

Title: Using tablets as tools for learner-generated drawings in the context of teaching the kinetic theory of gases

Year: $\quad 2014$

Version:

Please cite the original version:

Lehtinen, A., \& Viiri, J. (2014). Using tablets as tools for learner-generated drawings in the context of teaching the kinetic theory of gases. Physics education, $49(3)$, Article 344. https://doi.org/10.1088/0031-9120/49/3/344

All material supplied via JYX is protected by copyright and other intellectual property rights, and duplication or sale of all or part of any of the repository collections is not permitted, except that material may be duplicated by you for your research use or educational purposes in electronic or print form. You must obtain permission for any other use. Electronic or print copies may not be offered, whether for sale or otherwise to anyone who is not an authorised user. 


\title{
Using tablets as tools for learner-generated drawings in the context of teaching kinetic theory of gases
}

\author{
A Lehtinen and J Viiri \\ Department of Teacher Education, University of Jyväskylä, PO Box 35, 40014 Jyväskylän \\ Yliopisto, Finland
}

E-mail: antti.t.lehtinen@jyu.fi, jouni.viiri@jyu.fi

\begin{abstract}
Even though research suggests that the use of drawings could be an important part of learning science, learnergenerated drawings have not received much attention in physics classrooms. This article presents a method for recording students' drawings and group discussions using tablets. Compared to pen and paper, tablets offer unique benefits, which include the recording of the whole drawing process and of the discussion associated with the drawing. A study, which investigated the use of drawings and the need for guidance among Finnish upper secondary school students, is presented alongside ideas for teachers on how to see drawing in a new light.
\end{abstract}

\section{Introduction}

How often are students asked to examine a drawing from a textbook or by their teacher in physics classrooms? In contrast, how often are students asked to produce their own drawings? It is quite probable that the examination of drawings happens more often than the production of drawings. Physics teachers know that the use of visual materials (diagrams, graphs etc.) is very important both in physics and physics education. This is also supported by research (Ainsworth, Prain, \& Tytler, 2011) which suggests that it increases motivation to learning and deepen the understanding about the specific conventions of the visual material among other benefits. However, in science education, the focus is very often on interpreting drawings made by others (Ainsworth et al., 2011). Even when the students are told to draw, it is rare that they are encouraged to develop their own ways of drawing that could help them develop their understanding (Van Meter \& Garner, 2005).

Drawings are also a way to scaffold learning for students who have difficulties with text, such as immigrants or children with learning disabilities. They can even aid in the development of language skills (Hope, 2008). The use of drawings in combination with text as a learning strategy can also be seen as a use of multiple representations (MRs) in the classroom. The benefits of the utilisation of MRs have been reviewed in a recent article in this journal (Savinainen, Nieminen, Makynen, \& Viiri, 2013).

There have been some empirical studies on the benefits of the use of learner-generated drawings. A meta-analysis about research on learner-generated drawings has identified some common claims for its benefits (Van Meter \& Garner, 2005). These benefits include improvements in text comprehension, increased levels of involvement with the target content, and the use of higher-order thinking. Previous studies have indicated that students' drawings are more accurate when they are 
Using tablets as tools for learner-generated drawings in the context of teaching kinetic theory of gases

allowed to compare their drawing with another drawing (Van Meter, Aleksic, Schwartz, \& Garner, 2006). It has also been suggested that there is a link between the accuracy of student-generated drawings and learning outcomes (Van Meter \& Garner, 2005). However, this suggestion has only limited empirical support.

\section{Using tablets to study drawing}

The digital age has brought new possibilities for drawing, e.g. the use of tablets. These devices allow new ways of gathering information about students' knowledge, and teachers can use multimodal resources, including drawings, video, and audio. In particular, these technologies allow the teacher to capture the whole drawing process, from the first line to the last. When using pen and paper for drawing, the only information that the teacher receives is the final product, which is the finished drawing. There is usually no way to see how the student got to that drawing or what alternative types of drawing he/she tried before choosing the final one. The use of a tablet enables the whole drawing process to be compiled into a video that starts from a blank canvas and finishes with the final drawing. Furthermore, the students' discussions can also be recorded alongside the drawing when using tablets. This may give new insights to the students' content knowledge.

A special application is required to record drawings. The application used in the study reported in this paper was Educreations for the iPad (Educreations, 2013). This application was chosen because it is free, and the interface is simple and easy to utilise. The application is intended to create animated lessons but it can also be used for recording drawings and conversations. It has its limitations (e.g., the drawing tools are minimal) but it is good enough for basic drawings.

\section{Description of a study on learner-generated drawings}

Our study investigated how a group of Finnish upper secondary school physics students $(\mathbf{n}=\mathbf{3 6}$, aged 17-18) used drawings as a tool for sharing information in the context of kinetic theory of gases. More precisely, the effect of guidance on the accuracy of the drawing process was studied.

The subject for the students' drawings was the kinetic theory of gases and ideal gas law. The students had taken an optional physics course on thermodynamics a year before the study. This gave us a chance to study the effect that textbook illustrations have on the drawings. First, the students read a short text on the kinetic theory of gases and ideal gas. Second, they were asked to produce a drawing in which they represented ideal gas as well as they could, using a tablet. They also had to draw their answers to assignments, producing drawings that represented what happens in a gas when the volume of the gas container is reduced to half or when half of the gas is removed from the container.

The students were randomly placed in groups of two or three. The groups were randomly assigned to two different condition groups. The assisted group (AS group, 8 groups of two) were provided with another drawing (drawing c, in figure 2) to which they could compare their first drawings. 
Using tablets as tools for learner-generated drawings in the context of teaching kinetic theory of gases

The unassisted group (UA group, 7 groups of two and two groups of three) were not provided with this drawing. Figure 1 shows the study procedure.

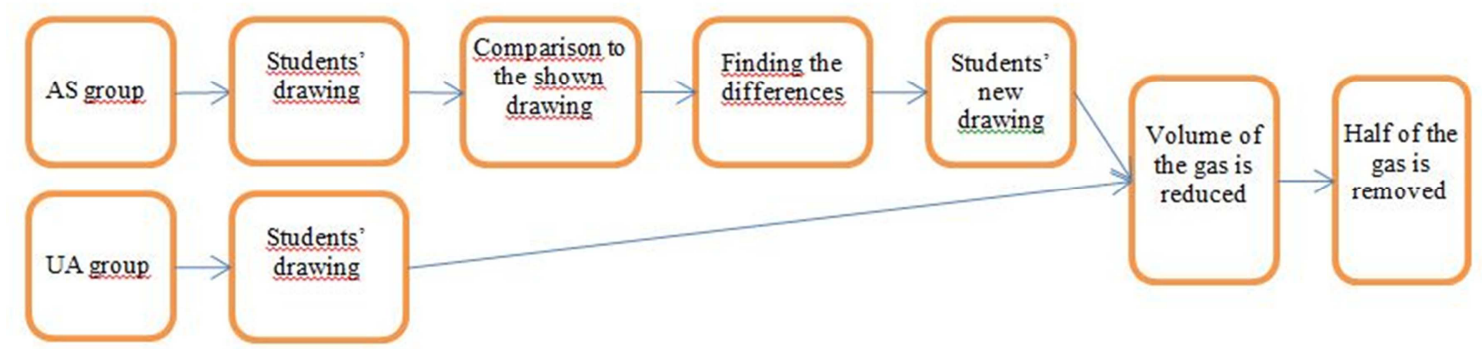

Figure 1: The study procedure for the two groups.

The accuracy of the drawings was determined by five predefined elements in the drawings. These five elements were divided into two categories and are presented in Table 1:

Table 1: The five drawing elements divided into two categories

\section{Elements Properties of the particles Collisions of the particles}

The particles are point-like $\quad \mathrm{X}$

The particles move randomly $\quad \mathrm{X}$

The particles move rectilinearly $\quad \mathrm{X}$

The particles collide with each $\quad \mathrm{X}$

other

The particles collide with the

$\mathrm{X}$

walls of the container 
Using tablets as tools for learner-generated drawings in the context of teaching kinetic theory of gases

\section{The results of the study}

The summary of the results regarding the assignments are provided in Table 2.

Table 2: The frequencies of the five elements in each group (UA or AS) combined into two categories. The maximum amount of elements in each category is presented in parenthesis.

\begin{tabular}{cccc}
\hline Assignment & Group & $\begin{array}{c}\text { 1. Properties of the particles } \\
\text { (maximum) }\end{array}$ & $\begin{array}{c}\text { 2. Collisions of the particles } \\
\text { (maximum) }\end{array}$ \\
\hline $\begin{array}{c}\text { Before the } \\
\text { comparison }\end{array}$ & UA & $18(24)$ & $11(16)$ \\
& AS & $23(27)$ & $10(18)$ \\
\hline After the & UA & $30(48)$ & $9(32)$ \\
comparison & AS & $47(54)$ & $22(36)$ \\
\hline
\end{tabular}

The $\chi 2$-test was conducted for the studying statistical difference between the qualities of the UA and AS groups' drawings and Cramer's V was calculated to determine the effect size. The p value of $\leq 0.05$ was considered statistically significant. There was no significant difference between the groups before the comparison $\left[\chi 2(1, \mathrm{~N}=51)=.36, \mathrm{p}=.55\right.$; Cramer's $\mathrm{V}=.08$ for category 1 and $\chi^{2}$ $(1, \mathrm{~N}=34)=.19, \mathrm{p}=.66$; Cramer's $\mathrm{V}=.08$ for category 2]. The AS group produced more accurate drawings than the UA group after the comparison $\left[\chi^{2}(1, \mathrm{~N}=102)=6.76, \mathrm{p}=.01\right.$; Cramer's $\mathrm{V}=.26$ for category 1 and $\chi^{2}(1, \mathrm{~N}=68)=6.16, \mathrm{p}=.02$; Cramer's $\mathrm{V}=.30$ for category 2 ]. The difference between the groups was significant and the effect size was small to medium.

Most of the students' drawings resembled the canonical illustrations of the kinetic theory of gases found in textbooks with the particles inside a closed container. It seems that the students remembered the style of the drawings from the textbook they had used to study thermodynamics. An observation could be made from the study data: even if the students had developed their own, uncanonical style of visualization before they saw the provided illustration, they produced more canonical drawings after seeing the illustration. Drawings of one pair before comparison (drawing a) and after comparison (drawing b) are shown in Figure 2. It seems that the students adopted the style of the provided illustration sketched by the researcher with the iPad (drawing c) and thought it to be the "correct style". This copying of styles has its upsides and its downsides. The students might have difficulty interpreting the canonical visualizations in science if they do not learn how to produce them themselves. On the other hand, students should be allowed to create their own types of visual representations because that helps them to process information. 
Using tablets as tools for learner-generated drawings in the context of teaching kinetic theory of gases

a)

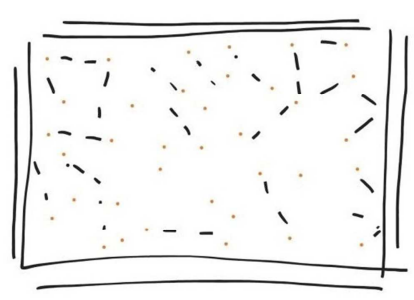

b)

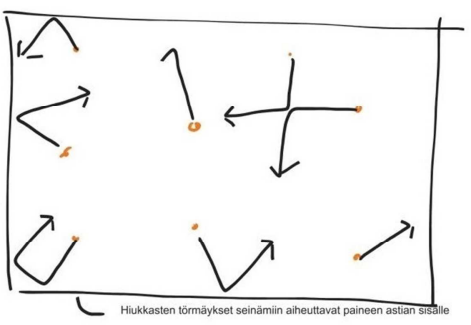

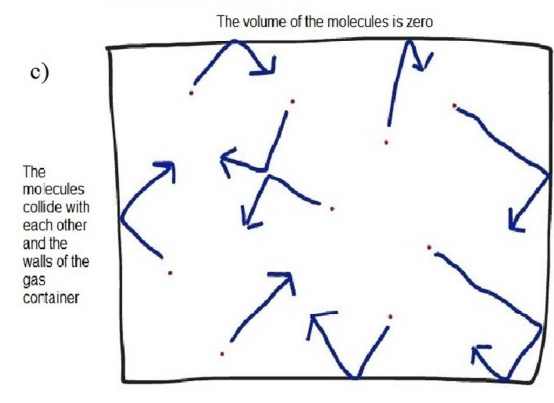

The molecules are in a constant random motion

Figure 2: Drawings a and $\mathrm{b}$ are made by the same group before and after the comparison to the provided drawing $\mathrm{c}$.

While drawing and discussing, two of the groups used equations. Interestingly, both of these groups used them incorrectly. One of the groups discovered their error and deleted the equation, but the other group did not notice their mistake and left the incorrect equation as a part of their drawing. In these kinds of situations, the strength of a tablet as a tool for recording the drawings is evident. The deletion could have been missed otherwise. It also highlights the strength of using drawings in learning: they force the students to process their knowledge in order to present it freely in a visual form.

Figure 3 shows the drawing process for an assignment that required the students to draw their conception of what happens in the gas when the volume of the gas is halved. First, the students draw a gas container with gas particles in it (drawing $d$ ) and then add arrows to visualize the movement of the particles (drawing e). One of the students tries to justify the decrease in pressure by using the (incorrect) equation that the students used to define pressure (drawing f). During the discourse, the student notices that there is something wrong in the equation. Instead of trying to attempt to correct the equation, the student just deletes it (drawing g). 
d)

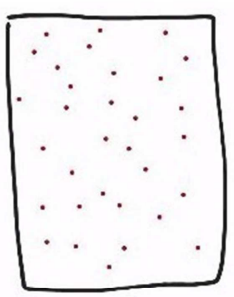

f)

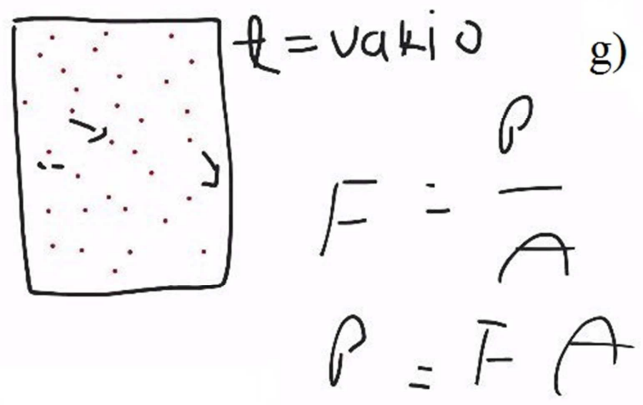

e)

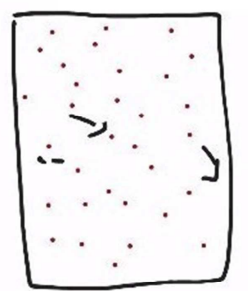

g)

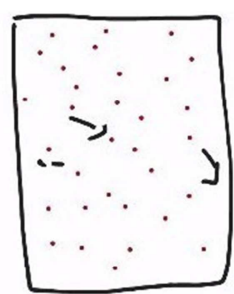

Figure 3: The drawing process for an assignment that required the students to draw their conception of what happens in gas when the volume of the gas is halved, divided into four drawings.

The talk associated with Figure 3 is presented in Excerpt 1.

Student A: So now the volume has decreased... well

Student B: But there is still the same number of the... point-like gas particles... and... what does that mean... [draws the container and the particles, drawing d] and that they pack themselves closer together and there are more collisions isn't that right?

A: Yeah so... the density increases so then there are more of those collisions between the container and the particles [draws the arrows, drawing e]

$B$ : Mmm... everything is moving

A: And then... wasn't the temperature kept constant?

$B$ : Yeah [writes $\mathrm{t}=$ vakio (Finnish), meaning temperature $\mathrm{t}=$ constant]

A: I'm going to write it like this... [draws the equation, drawing $\mathrm{f}$ ]

$B$ : And the increased collisions of the particles... or the increase in the number of collision increases the force that... is exerted to there and [it was because]

A: [it caused] the pressure to increase

$B:$ Because the force is the pressure divided by the area wasn't it... pressure is the force times the area... doesn't the area... decrease but it seems to increase A: Yeah

B: Like this... let's forget that...[deletes the equation, drawing g] nevertheless, the collisions increase and the force always increases as the pressure increases A: Yeah was there something else... no

Excerpt 1: The discussion between the students while engaged in the drawing process pictured in Figure 2.

The excerpt shows that student B is confused when his incorrect definition calls for the surface area of the container to increase when he knows that it decreases when the container's volume is de- 
Using tablets as tools for learner-generated drawings in the context of teaching kinetic theory of gases

creased. Student A confirms that the area should decrease. This causes B to discard his attempt to use the definition of pressure to validate the increase in pressure; he just uses the increased frequency of collision as validation for the increase. This is also a correct way to validate the increase in pressure.

\section{Benefits for teachers}

How can this study benefit teachers in their everyday work? More attention could be paid to guiding the students' drawings processes. Scott and Jewitt (2003) contend that teachers often pay more attention to the scientific accuracy of text produced by students than to the drawings they produce. Teachers also find it easier to guide the students' production of text than of drawings. The comparison method used in this study is one method to guide drawing. Driver (1983, p. 13) offers another example of how a teacher can guide the students, by giving them a clear question for which the students try to seek an answer through drawing.

The use of tablets gives teachers a unique method of gaining additional knowledge about the students' grasp of the content. The discussion associated with the drawings can put the drawings themselves in a new light. They also enable the teachers to let students use, for instance, photographs as a background for their drawings. For example, the students' knowledge of laboratory equipment could be tested by taking a picture of common laboratory equipment and instructing the students to write the names of the objects in the photograph. All in all, the use of tablets in education gives new possibilities for teacher and there is still a lot to be studied concerning their use.

\section{References}

Ainsworth, S., Vaughan Prain, \& Tytler, R. (2011). Drawing to learn in science. Science, 333(6046), 1096-1097. doi:http://dx.doi.org/10.1126/science.1204153

Driver, R. (1983). The pupil as scientist? (1st ed.). Buckingham, UK: Open University Press.

Educreations, Retrieved 05/20, 2013, from http://www.educreations.com/

Hope, G. (2008). Thinking and learning through drawing (1st ed.). Los Angeles: Sage Publishing Ltd. p. 15

Savinainen, A., Nieminen, P., Makynen, A., \& Viiri, J. (2013). Teaching and evaluation materials utilizing multiple representations in mechanics. Physics Education, 48(3), 372-377.

Scott, P., \& Jewitt, C. (2003). Talk, action and visual communication in teaching and learning science. School Science Review, 84, 117.

Van Meter, P., Aleksic, M., Schwartz, A., \& Garner, J. (2006). Learner-generated drawing as a strategy for learning from content area text. Contemporary Educational Psychology, 31(2), 142-166.

Van Meter, P., \& Garner, J. (2005). The promise and practice of learner-generated drawing: Literature review and synthesis. Educational Psychology Review, 17(4), 285-325. 